\title{
DIFFUSION PATH REPRESENTATION FOR TWO-PHASE TERNARY DIFFUSION COUPLES
}

\author{
by
}

M. A. Dayananda and R. Venkatasubramanian

\begin{abstract}
Several two-phase, solid-solid diffusion couples from diffusion studies in the ternary $\mathrm{Cu}-\mathrm{Ni}-\mathrm{Zn}, \mathrm{Fe}-\mathrm{Ni}-\mathrm{Al}$ and $\mathrm{Cu}-\mathrm{Ag}-\mathrm{Au}$ systems were investigated for their analytical representation on the basis of characteristic path parameters. The concentration profiles were examined in terms of relative concentration variables for cross-over compositions and internal consistency. The diffusion paths delineated single or double S-shaped curves crossing the straight line joining the terminal alloy compositions once or thrice. Cross-over compositions were identified in the individual phase regions or at an interface. Based on the symmetry between the path segments on either side of cross-over compositions, the paths were analytically represented with the aid of cross-over compositions and path slopes at these compositions, considered as path parameters. Expressions for the ratios of diffusion depths on the two sides of the Matano plane were derived in terms of cross-over compositions and the estimated ratios of diffusion depths were found to be consistent with those observed from the concentration profiles.
\end{abstract}

*M. A. Dayananda and R. Venkatasubramanian are, respectively, Professor of Materials Engineering and graduate student, Purdue University, W. Lafayette, IN 47907. 


\section{DISCLAIMER}

This report was prepared as an account of work sponsored by an agency of the United States Government. Neither the United States Government nor any agency Thereof, nor any of their employees, makes any warranty, express or implied, or assumes any legal liability or responsibility for the accuracy, completeness, or usefulness of any information, apparatus, product, or process disclosed, or represents that its use would not infringe privately owned rights. Reference herein to any specific commercial product, process, or service by trade name, trademark, manufacturer, or otherwise does not necessarily constitute or imply its endorsement, recommendation, or favoring by the United States Government or any agency thereof. The views and opinions of authors expressed herein do not necessarily state or reflect those of the United States Government or any agency thereof. 


\section{DISCLAIMER}

Portions of this document may be illegible in electronic image products. Images are produced from the best available original document. 


\section{INTRODUCTION}

For an isothermal, multicomponent diffusion couple, the sequence of compositions developed within the diffusion zone constitutes the diffusion path. For a solid-solid, single phase ternary diffusion couple, the diffusion path when plotted on a ternary isotherm is normally a time-invariant S-shaped curve crossing the straight line joining the terminal composition points at a cross-over composition. The ternary diffusion paths can also be presented in terms of relative concentration variables by plotting one concentration variable as a function of another $[1,2]$. Such paths for couples in the $\mathrm{Cu}-\mathrm{Ni}-\mathrm{Zn}$ and $\mathrm{Fe}-\mathrm{Ni}-\mathrm{Cr}$ systems have been examined for possible symmetry on the two sides of the cross-over composition and have been analytically represented $[1,3]$ with the aid of two characteristic path parameters, such as the cross-over composition and the path slope at that composition.

The main objective of this paper is to examine diffusion paths for several twophase ternary diffusion couples available in the literature for path parameters and extend the method of analytical, representation of paths on the basis of path parameters to two-phase couples. The couples examined in this study are selected from the diffusion investigations of Dayananda and coworkers in the Cu-Ni- $\mathrm{Zn}[4,5]$, and $\mathrm{Fe}-\mathrm{Ni}-\mathrm{Al}[6,7]$ systems and of Ziebold and Ogilvie in the $\mathrm{Cu}-\mathrm{Ag}-\mathrm{Au}$ system $[8]$ and are characterized by planar interfaces. The selected couples identified by their original designations are listed in Table $\mathrm{I}$.

The experimental concentration profiles for the various couples with concentrations expressed in terms of relative concentrations are examined for consistency on the basis of a consistency relation applicable to two-phase diffusion couples. The path parameters such as cross-over compositions and path slopes at these compositions are identified for the couples and employed for the path representation. The 
experimental concentration profiles, the diffusion paths and their analytical representation are presented and discussed below for the couples in the various systems in the order listed in Table I.

\section{TWO-PHASE DIFFUSION COUPLES}

\section{A. Diffusion Couples in the Cu-Ni-Zn System.}

The two two-phase couples selected in this system are from the studies of Kim and Dayananda [4,5] and correspond to couples assembled with $\gamma$ (cubic) and $\beta$ (bcc) $\mathrm{Cu}-\mathrm{Ni}-\mathrm{Zn}$ alloys and diffusion annealed at $775^{\circ} \mathrm{C}$. The concentration profiles $\left(C_{i}\right.$ vs $\mathrm{x})$ for the couple $\gamma_{3} / \beta_{8}$ are presented in Fig. 1 where the concentrations are expressed in atom percent as well as in relative concentration variables $Y_{i}$ defined by

$$
Y_{i}=\frac{C_{i}-C_{i}^{+}}{C_{i}^{-}-C_{i}^{+}} \quad(i=1,2,3)
$$

where $\mathrm{C}_{i}^{-}$and $\mathrm{C}_{i}^{-}$refer to the concentrations of component $\mathrm{i}$ in the two terminal alloys of the couple. $x_{0}$ and $x_{I}$ fefer to the locations of the Matano plane and the $\gamma / \beta$ interface, respectively. The $Y_{i}$ vs $x$ plots in Fig. $1(b)$ show that the profiles of

all components can be displayed together over the diffusion zone $\mathrm{L}^{-}$to $\mathrm{L}^{+}$such that $\mathrm{Y}_{\mathrm{i}}$ is 1 at $\mathrm{L}^{-}$and zero at $\mathrm{L}^{-}$for all components regardless of their flow directions in the diffusion zone. An interesting feature of these plots is the fact that all the profiles cross one another at two cross-over compositions, $\left(\mathrm{Y}_{\mathrm{c}}\right)_{\gamma}$ and $\left(\mathrm{Y}_{\mathrm{c}}\right)_{\beta}$ identified, respectively, at the cross-over planes, $\left(x_{c}\right)_{\gamma}$ and $\left(x_{c}\right)_{\beta}$ on the $\gamma$ and $\beta$ side of the $\gamma / \beta$ interface.

\section{DISCLAIMER}


On the basis of mass balance the $Y_{i}$ vs $x$ profiles need to satisfy the consistency relation [2] given by

$$
\int_{\mathbf{L}^{-}}^{\mathbf{L}^{+}}\left(\mathrm{Y}_{\mathrm{i}}-\mathrm{Y}_{\mathrm{j}}\right) \mathrm{dx}=\mathbf{0} \quad(\mathrm{i} \neq \mathrm{j})
$$

provided the molar volume variation in the diffusion zone can be ignored. For the plots in Fig 1(b), Eq. (2) yields:

$$
\int_{x=L^{-}}^{x=x_{1}}\left(Y_{i}-Y_{j}\right)_{\gamma} d x+\int_{x=x_{1}}^{x=L^{+}}\left(Y_{i}-Y_{j}\right)_{\beta} d x=0 \quad(i \neq j)
$$

where $\mathrm{x}_{1}$ corresponds to the location of the $\gamma / \beta$ interface. Thus, the areas $A, B, C$ and $\mathrm{D}$ between the $\mathrm{Zn}$ and $\mathrm{Cu}$ concentration profiles in Fig. $1(\mathrm{~b})$ need to satisfy the requirement: $A-B=D-C$. In other words, the net area difference between the two profiles on either side of the interface should be equal in magnitude. The area $(A-B)$ matched with the area $(D-C)$ with a difference of about $16 \%$. Similar degree of matching was observed for the areas between the $\mathrm{Cu}$ and $\mathrm{Zn}$ profiles on the two sides of the interface.

The experimental diffusion path for the couple $\gamma_{3} / \beta_{8}$ obtained by plotting $\mathrm{Y}_{\mathrm{Zn}}$ vs $\mathrm{Y}_{\mathrm{Cu}}$ is presented in Fig. 1(c). The composition data indicated by points reveal two S-shaped parts for the path, one in each phase region. These parts cross the straight line joining the terminal compositions indicated by $\mathrm{Y}_{\mathrm{i}}=0$ and $\mathrm{Y}_{\mathrm{i}}=1$ at the two cross-over compositions, $\left(\mathrm{Y}_{\mathrm{c}}\right)_{\gamma}$ and $\left(\mathrm{Y}_{\mathrm{c}}\right)_{\beta}$. In addition, the virtual portion of the path drawn between the composition points for the phases at the interface exhibits a virtual cross-over at the composition identified as $\left(\mathrm{Y}_{\mathrm{c}}\right)_{\mathrm{I}}$. Hence, the path can be considered to have four segments $S_{1}, S_{2}, S_{3}$ and $S_{4}$. If the segments on the two sides of each of the cross-over compositions, $\left(\mathrm{Y}_{\mathrm{c}}\right)_{\gamma}$ and $\left(\mathrm{Y}_{\mathrm{c}}\right)_{\beta}$, are considered 
symmetric to each other with a change of scale, they can be represented by expressions similar to those employed for single phase ternary diffusion paths $[1,3]$. The expressions for the segments, $S_{1}, S_{2}, S_{3}$ and $S_{4}$ are respectively given by:

$$
\begin{aligned}
& {\left[\frac{\mathrm{Y}_{\mathrm{Zn}_{\mathrm{n}}}}{\left(\mathrm{Y}_{\mathrm{c}}\right)_{\beta}}\right]^{\mathrm{p}}=\left[\frac{\mathrm{Y}_{\mathrm{Cu}}}{\left(\mathrm{Y}_{\mathrm{c}}\right)_{\beta}}\right] \quad\left[\left(0 \leq \mathrm{Y}_{\mathrm{Zn}}, \mathrm{Y}_{\mathrm{Cu}} \leq\left(\mathrm{Y}_{\mathrm{c}}\right)_{\beta}\right)\right]} \\
& \left\lfloor\frac{\left(\mathrm{Y}_{\mathrm{c}}\right)_{\mathrm{I}}-\mathrm{Y}_{\mathrm{Zn}_{\mathrm{n}}}}{\left(\mathrm{Y}_{\mathrm{c}}\right)_{\mathrm{I}}-\left(\mathrm{Y}_{\mathrm{c}}\right)_{\beta}}\right]^{p}=\left\lfloor\frac{\left(\mathrm{Y}_{\mathrm{c}}\right)_{\mathrm{I}}-\mathrm{Y}_{\mathrm{Cu}}}{\left(\mathrm{Y}_{\mathrm{c}}\right)_{\mathrm{I}}-\left(\mathrm{Y}_{\mathrm{c}}\right)_{\beta}}\right] \quad\left[\left(\mathrm{Y}_{\mathrm{c}}\right)_{\beta} \leq \mathrm{Y}_{\mathrm{Zn}_{\mathrm{n}}}, \mathrm{Y}_{\mathrm{Cu}} \leq\left(\mathrm{Y}_{\mathrm{c}}\right)_{\mathrm{I}}\right] \\
& \left\lfloor\frac{\mathrm{Y}_{\mathrm{Zn}_{\mathrm{n}}}-\left(\mathrm{Y}_{\mathrm{c}}\right)_{\mathrm{I}}}{\left(\mathrm{Y}_{\mathrm{c}}\right)_{\gamma}-\left(\mathrm{Y}_{\mathrm{c}}\right)_{\mathrm{I}}^{\mathrm{p}}}\right]^{\mathrm{f}}=\left[\frac{\mathrm{Y}_{\mathrm{Cu}}-\left(\mathrm{Y}_{\mathrm{c}}\right)_{\mathrm{I}}}{\left(\mathrm{Y}_{\mathrm{c}}\right)_{\gamma}-\left(\mathrm{Y}_{\mathrm{c}}\right)_{\mathrm{I}}}\right] \quad\left[\left(\mathrm{Y}_{\mathrm{c}}\right)_{\mathrm{I}} \leq \mathrm{Y}_{\mathrm{Zn}_{\mathrm{n}}}, \mathrm{Y}_{\mathrm{Cu}} \leq\left(\mathrm{Y}_{\mathrm{c}}\right)_{\gamma}\right]
\end{aligned}
$$

and

$$
\left[\frac{1-\mathrm{Y}_{\mathrm{Zn}}}{1-\left(\mathrm{Y}_{\mathrm{c}}\right)_{\gamma}}\right]^{\mathrm{p}}=\left[\frac{1-\mathrm{Y}_{\mathrm{Cu}}}{1-\left(\mathrm{Y}_{\mathrm{c}}\right)_{\gamma}}\right] \quad\left[\left(\mathrm{Y}_{\mathrm{c}}\right)_{\gamma} \leq \mathrm{Y}_{\mathrm{Zn}}, \mathrm{Y}_{\mathrm{Cu}} \leq 1\right]
$$

The path slopes $(1 / n)_{\gamma}$ and $(1 / n)_{\beta}$ at the cross-over compositions $\left(Y_{\mathrm{c}}\right)_{\gamma}$ and $\left(Y_{\mathrm{c}}\right)_{\beta}$, respectively, in Fig. 1(c) are about equal and is identified as $1 / \mathrm{n}$. The various path parameters have been reported in Table $I$ and were employed to calculate the diffusion path for the couple $\gamma_{3} / \beta_{8}$. The calculated path is also shown in Fig. 1(c) as a dashed curve.

The concentration profiles and the diffusion path for the couple $\gamma_{3} / \beta_{1}$ are presented in Fig. 2. As can be seen in Fig. 2(b) the path exhibits two cross-over compositions $\left(Y_{c}\right)_{\gamma}$ and $\left(Y_{c}\right)_{\beta}$ in the $\gamma$ and $\beta$ phases, respectively, and a virtual cross-over composition $\left(\mathrm{Y}_{\mathrm{c}}\right)_{1}$ across the interface. The path can be considered to have four segments $S_{1}, S_{2}, S_{3}$ and $S_{4}$ and can be analytically represented with the 
aid of path parameters reported in Table I. The path calculated from these parameters on the basis of Eqs. (4-7) is also shown in Fig. 2(b).

For the couples $\gamma_{3} / \beta_{8}$ and $\gamma_{3} / \beta_{1}$ the cross-over compositions satisfy the relation:

$$
\frac{\left(Y_{c}\right)_{I}}{1-\left(Y_{c}\right)_{1}}=\frac{\left(Y_{c}\right)_{\beta}}{1-\left(Y_{c}\right)_{\gamma}}
$$

Hence, the number of independent parameters necessary for the representation of the path is three consisting of two cross-over compositions and a path slope at one of the cross-over compositions. The significance of Eq. (8) is discussed in a later sec-. tion.

\section{B. Diffusion Couples in the Fe-Ni-Al System.}

Two diffusion couples, investigated by Cheng and Dayananda [6,7] with $\gamma(\mathrm{fcc})$ and $\beta$ (bcc) $\mathrm{Fe}-\mathrm{Ni}-\mathrm{Al}$ alloys at $1000^{\circ} \mathrm{C}$ were examined in this study. The original designations of these couples are $\gamma_{2} / \beta_{27}$ and $\gamma_{6} / \beta_{12}$ as indicated in Table I.

The concentration profiles for the couple $\gamma_{2} / \beta_{27}$ are presented in Figs. 3(a) and 3(b) with concentrations expressed in atom percent and relative concentration units, respectively. The $Y_{i}$ vs $x$ plots do not exhibit cross-over compositions on either side of the $\gamma / \beta$ interface. However, there is a virtual cross-over of the profiles at the interface which can be appreciated clearly in the diffusion path for the couple presented in Fig. 3(c) as a plot of $\mathrm{Y}_{\mathrm{Ni}}$ vs $\mathrm{Y}_{\mathrm{Al}}$. The path is S-shaped and consists of two segments $S_{1}$ and $S_{2}$ for the $\beta$ and $\gamma$ phase regions, respectively. The virtual part of the path between the composition points for the phases at the interface exhibits a cross-over composition identified as $\left(\mathrm{Y}_{\mathrm{c}}\right)_{\mathrm{I}}$ and the corresponding path slope at $\left(Y_{c}\right)_{I}$ is denoted by $(1 / n)_{I}$. On the basis of path parameters $\left(Y_{c}\right)_{I}$ and $(n)_{I}$ 
reported in Table I, the diffusion path can be analytically represented from the relations:

$$
\left[\frac{Y_{N_{i}}}{\left(Y_{c}\right)_{I}}\right]^{(n)_{1}}=\left[\frac{Y_{A l}}{\left(Y_{c}\right)_{I}}\right] \quad\left[0 \leq Y_{N_{i}}, Y_{A l} \leq\left(Y_{c}\right)_{I}\right]
$$

and

$$
\left[\frac{1-Y_{N i}}{1-\left(Y_{c}\right)_{I}}\right]^{(n)_{I}}=\left[\frac{1-Y_{A I}}{1-\left(Y_{c}\right)_{I}}\right] \quad\left[\left(Y_{c}\right)_{I} \leq Y_{N i}, Y_{A l}, \leq 1\right]
$$

The path calculated from Eqs. (9) and (10) is also shown in Fig. 3(c).

Fig. 4 presents the concentration profiles as well as the diffusion path for the couple $\gamma_{6} / \beta_{12}$. The $Y_{i}$ vs $x$ plots in Fig. 4(b) exhibit a cross-over composition $\left(Y_{c}\right)_{\beta}$ on the $\beta$-side of the interface. This is also apparent in the diffusion path presented in Fig. 4(c) as a plot of $Y_{A J}$ vs $Y_{F e}$. The path consists of two segments $S_{1}$ and $S_{2}$ which can be considered to lie on an S-shaped curve exhibiting a cross-over composition $\left(\mathrm{Y}_{\mathrm{c}}\right)_{\beta}$ on the $\beta$ side. On the basis of the path parameters $\left(\mathrm{Y}_{\mathrm{c}}\right)_{\beta}$ and the path slope $1 /(\mathrm{n})_{\beta}$ at $\left(\mathrm{Y}_{\mathrm{c}}\right)_{\beta}$, the path can be calculated from the relations:

$$
\begin{gathered}
{\left[\frac{\mathrm{Y}_{\mathrm{Al}}}{\left(\mathrm{Y}_{\mathrm{c}}\right)_{\beta}}\right]^{(\mathrm{n})_{\beta}}=\left[\frac{\mathrm{Y}_{\mathrm{Fe}}}{\left(\mathrm{Y}_{\mathrm{c}}\right)_{\beta}}\right] \quad\left[0 \leq \mathrm{Y}_{\mathrm{Al}} \mathrm{Y}_{\mathrm{Fe}}, \leq\left(\mathrm{Y}_{\mathrm{c}}\right)_{\beta}\right]} \\
{\left[\frac{\left(1-\mathrm{Y}_{\mathrm{Al}}\right)}{1-\left(\mathrm{Y}_{\mathrm{c}}\right)_{\beta}}\right]^{(\mathrm{n})_{\beta}}=\left[\frac{1-\mathrm{Y}_{\mathrm{Fe}}}{1-\left(\mathrm{Y}_{\mathrm{c}}\right)_{\beta}}\right] \quad\left[\left(\mathrm{Y}_{\mathrm{c}}\right)_{\beta} \leq \mathrm{Y}_{\mathrm{Al}}, \mathrm{Y}_{\mathrm{Fe}} \leq 1.0\right]}
\end{gathered}
$$

The path calculated from Eqs. (11) and (12) correspond to the dashed curve in Fig. $4(c)$. 


\section{Diffusion Couples in the Cu-Ag-Au System}

Concentration profiles as well as diffusion paths for two $\alpha$ (fcc)/ $\alpha^{\prime}$ (fcc) Cu-AgAu couples, $80 \mathrm{C} / 80 \mathrm{~S}$ and $60 \mathrm{C} / \mathrm{S}$, investigated by Ziebold and Ogilvie $[8]$ and listed in Table $I$ are presented in Figs. 5 and 6, respectively. The diffusion path for the couple $80 \mathrm{C} / 80 \mathrm{~S}$ is shown as a plot of $\mathrm{Y}_{\mathrm{Cu}}$ vs $\mathrm{Y}_{\mathrm{Ag}}$, while that of the couple $60 \mathrm{C} / \mathrm{S}$, as a plot of $Y_{A_{8}}$ vs $Y_{C_{4}}$. Each of the paths consists of two segments $S_{1}$ and $S_{2}$.

Although the composition points on these segments are quite apart separated by the interface region, they form part of an S-shaped curve exhibiting a virtual cross-over composition identified by $\left(\mathrm{Y}_{\mathrm{c}}\right)_{\mathrm{I}}$. From the values of $\left(\mathrm{Y}_{\mathrm{c}}\right)_{\mathrm{I}}$ and of the corresponding path slope $(1 / n)_{1}$ for the couple $80 \mathrm{C} / 80 \mathrm{~S}$, the diffusion path segments $S_{1}$ and $S_{2}$ were calculated on the basis of the relations:

$$
\begin{gathered}
{\left[\frac{Y_{C_{u}}}{\left(Y_{c}\right)_{I}}\right]^{(n)_{I}}=\left[\frac{Y_{A_{g}}}{\left(Y_{c}\right)_{I}}\right] \quad\left[0 \leq Y_{C u}, Y_{A_{g}} \leq\left(Y_{c}\right)_{I}\right]} \\
{\left[\frac{1-Y_{C_{u}}}{1-\left(Y_{c}\right)_{I}}\right]^{(n)_{I}}=\left[\frac{1-Y_{A_{g}}}{1-\left(Y_{c}\right)_{I}}\right] \quad\left[\left(Y_{c}\right)_{I} \leq Y_{C u}, Y_{A g} \leq 1\right]}
\end{gathered}
$$

and shown in Fig. 5(b). Similarly, the dashed curve in Fig. 6(b) represents the path calculated for the couple $60 \mathrm{C} / \mathrm{S}$ on the basis of relations obtained by interchanging $Y_{C u}$ and $Y_{A g}$ in Eqs. (13) and (14) and utilizing the path parameters, $\left(Y_{c}\right)_{I}$ and $(n)_{I}$ reported for the couple in Table $I$.

\section{DISCUSSION}

The two-phase ternary diffusion couples with planar interfaces examined in this study have clearly shown that their concentration profiles and diffusion paths can be conveniently displayed in terms of relative concentration variables. Since there 
exist only two independent concentration variables for a ternary system, diffusion paths are shown as plots of one relative concentration variable as a function of another. Since the concentration profiles are discontinuous at an interface, the path for a two-phase couple invariably consists of two parts describing sequences of compositions developed in the individual phases of a couple. These parts of the path are normally connected by a path crossing across a two-phase region on the. basis of local equilibrium at a planar interface [0].

One of the major observations of this study is that the diffusion paths displayed in terms of relative concentration variables $Y_{i}$ delineate parts of a single or double S-shaped curve as shown in Figs. 1-6 for the various couples. These curves cross the straight line joining the terminal $Y_{i}$ values of zero and 1 , one or more times. The diffusion paths examined in this study are characterized by:

1. one cross-over composition in each phase and one virtual cross-over at the interface as exhibited by the couples in Figs. 1 and 2;

2. one virtual cross-over composition as indicated for the couples in Figs. 3,5 and 6; and

3. one cross-over composition in one of the phase regions for the couple shown in Fig. 4.

Another important observation on diffusion paths is that the adjacent path segments on the two sides of a cross-over composition appear symmetric with an appropriate change of scale and can be analytically represented or calculated with the aid of path parameters, such as cross-over compositions and path slopes at such compositions. The relations employed for such representations in Eqs. (4-14) are similar to those employed $[1]$ for the description of single phase ternary diffusion 
paths and the agreement between the calculated and experimental paths is considered quite satisfactory. The number of path parameters necessary for the representation of paths is two for couples exhibiting one cross-over composition, and four for couples exhibiting three cross-over compositions. For the paths characterized by three cross-over compositions, the number of parameters necessary for the path representation can be reduced to three on the basis of Eq. (8).

An assumption made in the analysis and representation of the two-phase couples is that the difference in the molar volume of the two phases in the diffusion zone may be neglected. For the $\mathrm{Cu}-\mathrm{Ni}-\mathrm{Zn}$ couples, the molar volumes of the $\beta(\mathrm{bcc})$ and $\gamma$ (cubic) phases differ little and are estimated to be about 8.0 and $8.1 \mathrm{cc} / \mathrm{g} \cdot \mathrm{mole}$, respectively [4]. For the $\gamma(\mathrm{fcc})$ and $\beta$ (bcc) $\mathrm{Fe}-\mathrm{Ni}-\mathrm{Al}$ alloys, the molar volumes are about 6.8 and $7.1 \mathrm{cc} / \mathrm{g} \cdot \mathrm{mole}$, respectively $[6,10]$ and hence differ by less than $5 \%$. Based on the molar volumes of $\mathrm{Cu}$ and $\mathrm{Ag}$, the variation in molar volume in the diffusion zone of the $\mathrm{Cu}-\mathrm{Ag}-\mathrm{Au}$ couples may be more than 35 percent. However, the employment of relative concentration variables for the description of diffusion paths for the $\mathrm{Cu}-\mathrm{Ag}-\mathrm{Au}$ couples still brings out the symmetry between the path segments, as can be seen in Figs. 5(b) and 6(b).

The single cross-over composition $Y_{c}$ normally observed for a single phase ternary, solid-solid diffusion couple can be interpreted as the common average relative concentration for each component over the diffusion zone and can be related to the relative depths of diffusion in the terminal alloys [2]. Similarly, for the two-phase couples exhibiting either one or more cross-over compositions as indicated in Table I, inter-relations can be derived between the cross-over compositions and the effective diffusion depths on the two sides of the Matano plane $x_{0}$.

On the basis of mass balance the area under the concentration profile $Y_{\mathrm{i}}$ vs $\mathrm{x}$ over the effective diffusion zone $\mathrm{L}^{-}$to $\mathrm{L}^{+}$for any component $\mathrm{i}$ is equal to $\left(x_{0}-\mathrm{L}^{-}\right)$ 
[2]. Hence, the average relative concentration $\bar{Y}_{i}$ over the diffusion zone is given by

$$
\bar{Y}_{i}=\frac{\left(x_{o}-L^{-}\right)}{\left(L^{+}-L^{-}\right)}
$$

for all components. Similarly,

$$
\left(1-\bar{Y}_{i}\right)=\frac{\left(L^{+}-x_{0}\right)}{\left(L^{+}-L^{-}\right)}
$$

For a couple such as $\gamma_{3} / \beta_{8}$ shown in Fig. l,

$$
\left(x_{o}-L^{-}\right)=\left(x_{0}-L^{-}\right)\left(Y_{c}\right)_{\gamma}+\left[1-\left(Y_{c}\right)_{\gamma}\right]\left(x_{0}-L^{-}\right)
$$

and

$$
\left(L^{+}-x_{0}\right)=\left(Y_{c}\right)_{\beta}\left(L^{+}-x_{0}\right)+\left[1-\left(Y_{c}\right)_{\beta}\right]\left(L^{+}-x_{0}\right)
$$

If the locations $\mathrm{L}^{-}$and $\mathrm{L}^{+}$for the diffusion zone are chosen such that

$$
\left[1-\left(\mathrm{Y}_{\mathrm{c}}\right)_{\gamma}\right]\left(\mathrm{x}_{\mathrm{o}}-\mathrm{L}^{-}\right)=\left(\mathrm{Y}_{\mathrm{c}}\right)_{\beta}\left(\mathrm{L}^{+}-\mathrm{x}_{\mathrm{o}}\right)
$$

the ratio of the diffusion depths on the two sides of the Matano plane is given by

$$
\frac{\prime\left(\mathrm{x}_{\mathrm{o}}-\mathrm{L}^{-}\right)}{\left(\mathrm{L}^{+}-\mathrm{x}_{\mathrm{o}}\right)}=\frac{\left(\mathrm{Y}_{\mathrm{c}}\right)_{\beta}}{1-\left(\mathrm{Y}_{\mathrm{c}}\right)_{\gamma}}
$$

Eq. (20) also follows on substitution of Eq. (19) in Eq. (17) or Eq. (18). From Eqs. (15), (16) and (20), it follows that

$$
\overline{\mathrm{Y}}_{\mathrm{i}}=\frac{\left(\mathrm{Y}_{\mathrm{c}}\right)_{\beta}}{\left[1-\left(\mathrm{Y}_{\mathrm{c}}\right)_{\gamma}+\left(\mathrm{Y}_{\mathrm{c}}\right)_{\beta}\right]}
$$

and

$$
\left(1-\bar{Y}_{\mathrm{i}}\right)=\frac{\left[1-\left(\mathrm{Y}_{\mathrm{c}}\right)_{\gamma}\right]}{\left(1-\left(\mathrm{Y}_{\mathrm{c}}\right)_{\gamma}+\left(\mathrm{Y}_{\mathrm{c}}\right)_{\beta}\right]}
$$

Also, 


$$
\frac{\bar{Y}_{i}}{1-\bar{Y}_{i}}=\frac{\left(Y_{c}\right)_{\beta}}{1-\left(Y_{c}\right)_{\gamma}}
$$

The virtual cross-over composition $\left(\mathrm{Y}_{\mathrm{c}}\right)_{1}$ also represents the common average relative concentration $\overline{\mathbf{Y}}_{\mathfrak{i}}$, if

$$
\frac{\left(\mathrm{Y}_{\mathrm{c}}\right)_{\mathrm{I}}}{1-\left(\mathrm{Y}_{\mathrm{c}}\right)_{\mathrm{I}}}=\frac{\left(\mathrm{x}_{\mathrm{o}}-\mathrm{L}^{-}\right)}{\left(\mathrm{L}^{+}-\mathrm{x}_{\mathrm{o}}\right)}
$$

In the light of Eq. (20), Eq. (24) is equivalent to Eq. (8) which was satisfied by the $\mathrm{Cu}-\mathrm{Ni}-\mathrm{Zn}$ couples, $\gamma_{3} / \beta_{8}$ and $\gamma_{3} / \beta_{1}$. Hence, $\left(\mathrm{Y}_{\mathrm{c}}\right)_{\mathrm{I}}$ can be considered as the common , average relative concentration $\bar{Y}_{i}$ over the diffusion zone, and can be calculated from $\left(\mathrm{Y}_{\mathrm{c}}\right)_{\gamma}$ and $\left(\mathrm{Y}_{\mathrm{c}}\right)_{\beta}$ on the basis of Eq. (21). For the Cu-Ni-Zn couples, only two of the three cross-over compositions are independent and values of the ratio of the diffusion depths, $\left(x_{0}-L^{-}\right) /\left(L^{+}-x_{0}\right)$ calculated from Eq. (20) are also reported in Table I.

For the couples exhibiting only a virtual cross-over composition $\left(Y_{c}\right)_{I}$, Eq. (24) was employed for the estimation of the ratio of the diffusion depths. Such values have been reported for the couples $80 \mathrm{C} / 80 \mathrm{~S}, 60 \mathrm{C} / \mathrm{S}$, and $\gamma_{2} / \beta_{27}$ in Table I. For the couple $\gamma_{b} / \beta_{12}$ indicating a single cross-over composition in the $\beta$ phase, the value of $\left(\mathrm{Y}_{\mathrm{c}}\right)_{\beta}$ was used in the place of $\left(\mathrm{Y}_{\mathrm{c}}\right)_{\mathrm{I}}$ in Eq. (24) for the estimation of diffusion depth ratio reported in Table $I$. The calculated values of $\left(x_{0}-L^{-}\right) /\left(L^{+}-x_{0}\right)$ for the individual couples appear quite consistent with the relative diffusion depths observed in their concentration profiles presented in Figs. 1-6. 


\section{CONCLUSIONS}

The main conclusions that follow from this study of the concentration profiles and diffusion paths for the two-phase couples selected in the $\mathrm{Cu}-\mathrm{Ni}-\mathrm{Zn}, \mathrm{Fe}-\mathrm{Ni}-\mathrm{Al}$ and $\mathrm{Cu}-\mathrm{Ag}-\mathrm{Au}$ systems can be summarized as follows.

1. The diffusion paths for two-phase, ternary solid-solid diffusion couples . displayed as plots of one relative concentration variable as a function of another correspond to single or double S-shaped curves.

2. The diffusion paths cross the straight line joining the terminal alloy compositions once or thrice. Hence, the paths can be characterized by one or three cross-over compositions.

3. For the single S-shaped paths, the one cross-over composition can be in one of the single phase regions or can be virtual at an interface. For the double S-shaped paths, the three cross-over compositions correspond to one crossover composition in each of the two individual phases and one virtual crossover composition at the'interface.

4. Adjacent path segments on the two sides of a cross-over composition display symmetry with an appropriate change of scale. Hence, the paths can be analytically represented on the basis of path parameters such as cross-over compositions and path slopes at such compositions.

5. The ratio of the diffusion depths on the two sides of the Matano plane can be estimated from the cross-over compositions. 


\section{ACKNOWLEDGMENT}

This work was supported by the Department of energy under contract DEAC02-81ER10814 and is based on a dissertation submitted by R. Venkatasubramanian to Purdue University in partial fulfillment of the requirements for the M.S. degree in Metallurgical Engineering.

\section{REFERENCES}

1. M. A. Dayananda and C. W. Kim, Scripta Met., 1982, vol. 16, p. 815.

2. M. A. Dayananda, Metall. Trans. A, 1983, vol. 14A, p. 1851.

3. J. G. Duh and M. A. Dayananda, Diffusion \& Defect Data, 1985, vol. 39, p. 1.

4. C. W. Kim and M. A. Dayananda, Metall. Trans. A, 1984, vol. 15A, p. 649.

5. C. W. Kim, Ph.D. Thesis, School of Materials Engineering, Purdue University, 1982.

6. G. H. Cheng and M. A. Dayananda, Metall. Trans. A, 1979, vol. 10A, p. 1407.

7. G. H. Cheng, Ph.D. Thesis, School of Materials Engineering, Purdue University, 1976.

8. T. O. Ziebold and R. E. Ogilvie, Trans. TMS-AIME, 1967, vol. 239, p. 942.

9. J. S. Kirkaldy and L. C. Brown, Can. Metall. Quarterly 1963, vol. 2, p. 89.

10. W. B. Pearson, Handbook of Lattice Spacing and Structure of Metals, Pergamon Press, 1958, vol. 1, p. 347. 
TABLE I. Two-phase ternary diffusion couples selected for the path representation.

\begin{tabular}{|c|c|c|c|c|c|c|}
\hline \multirow{2}{*}{$\begin{array}{l}\text { System } \\
\text { [Ref. No] } \\
\text { and } \\
\text { Phases }\end{array}$} & \multirow{2}{*}{$\begin{array}{l}\text { Original Couple Designation } \\
\text { With } \\
\text { Terminal Alloy Compositions } \\
\text { (at. pct) }\end{array}$} & \multirow{2}{*}{$\begin{array}{l}\text { Diffusion } \\
\text { Temperature } \\
\text { and } \\
\text { Time }\end{array}$} & \multirow{2}{*}{$\begin{array}{l}\text { Number } \\
\text { of } \\
\text { Cross-overs }\end{array}$} & \multicolumn{2}{|c|}{ Path Parameters } & \multirow{2}{*}{$\begin{array}{l}\left(x_{0}-L^{-}\right) \\
\left(L^{+}-x_{0}\right) \\
{[\text { from Eq. }(20)} \\
\text { or Eq. (24)] }\end{array}$} \\
\hline & & & & $Y_{c}$ & $n$ & \\
\hline \multirow{2}{*}{$\begin{array}{l}\text { CU-Ni-Zn } \\
{[4,5]} \\
Y(\text { cubtc }) \\
\text { B(bcc) }\end{array}$} & $\gamma_{3}(23.4 C u-76.6 Z n) / \beta_{8}(55 C u-45 Z n)$ & $775^{\circ} \mathrm{C} ; 2 \mathrm{~h}$ & 3 & $\begin{array}{l}\left(Y_{C}\right)_{Y}=0.66 \\
\left(Y_{C}\right)_{B}=0.16 \\
\left(Y_{C}\right)_{I}=0.32\end{array}$ & $n=2.17$ & 0.47 \\
\hline & $\gamma_{3}(23.4 C u-76.6 Z n) / \beta_{1}(30.5 C U-20.8 N 1-48.7 Z n)$ & $775^{\circ} \mathrm{C} ; 2 \mathrm{~h}$ & 3 & $\begin{array}{l}\left(Y_{c}\right)_{Y}=0.76 \\
\left(Y_{c}\right)_{B}=0.15 \\
\left(Y_{c}\right)_{1}=0.38\end{array}$ & $n=2.27$ & 0.62 \\
\hline $\begin{array}{l}\text { Fe-Ni-A1 } \\
{[6,7]} \\
\gamma(f c c) \\
B(b c c)\end{array}$ & $\begin{array}{l}\gamma_{2}(19.2 \mathrm{Fe}-80.8 \mathrm{Ni}) / \beta_{27}(12.8 \mathrm{Fe}-45.2 \mathrm{Ni}-42 \mathrm{Al}) \\
\gamma_{6}(60.4 \mathrm{Fe}-39.6 \mathrm{NI}) / \mathrm{B}_{12}(16 \mathrm{Fe}-49.7 \mathrm{NI}-34.3 \mathrm{AI})\end{array}$ & $\begin{array}{l}1000^{\circ} \mathrm{C} ; 24 \mathrm{~h} \\
1000^{\circ} \mathrm{C} ; 72 \mathrm{~h}\end{array}$ & $\begin{array}{l}1 \\
1\end{array}$ & $\begin{array}{l}\left(Y_{C}\right)_{I}=0.5 \\
\left(Y_{C}\right)_{B}=0.18\end{array}$ & $\begin{array}{l}(n)_{I}=2.4 \\
(n)_{B}=1.7\end{array}$ & $\begin{array}{l}1.0 \\
0.22\end{array}$ \\
\hline $\begin{array}{c}\mathrm{Cu}-\mathrm{Ag}-\mathrm{Au} \\
{[8]} \\
\left.\alpha^{\{} \mathrm{fcc}\right) \\
\alpha^{\prime}(\mathrm{fcc})\end{array}$ & $\begin{array}{l}80 C(92.5 C u-7.5 A u) / 805(88.5 A g-11.5 A u) \\
60 C(82 C u-18 A u) / S(100 A g)\end{array}$ & $\begin{array}{l}725^{\circ} \mathrm{C} ; 48 \mathrm{~h} \\
727^{\circ} \mathrm{C} ; 60 \mathrm{~h}\end{array}$ & $i$ & $\begin{array}{l}\left(Y_{c}\right)_{I}=0.55 \\
\left(Y_{c}\right)_{I}=0.55\end{array}$ & $\begin{array}{l}(n)_{I}=1.3 \\
\left(n_{I}\right)=1.2\end{array}$ & $\begin{array}{l}1.22 \\
1.22\end{array}$ \\
\hline
\end{tabular}




\section{FIGURE CAPTIONS}

Fig. 1. Concentration profiles for the $\mathrm{Cu}-\mathrm{Ni}-\mathrm{Zn}$ couple $\gamma_{3} / \beta_{8}$ with concentrations expressed in (a) atom percent and (b) relative concentrations $Y_{i} ;$ (c) a plot of $\mathrm{Y}_{\mathrm{Zn}}$ vs $\mathrm{Y}_{\mathrm{Cu}}$ delineating a double S-shaped diffusion path with 3 crossover compositions $\left(Y_{c}\right)_{\gamma},\left(Y_{c}\right)_{\beta}$ and $\left(Y_{c}\right)_{I}$. The experimental data points enclosed in circles correspond to compositions of the phases at the interface. The calculated path is shown by the dashed curve.

Fig. 2. (a) Concentration profiles and (b) double S-shaped diffusion path for the $\mathrm{Cu}-\mathrm{Ni}-\mathrm{Zn}$ couple $\gamma_{3} / \beta_{1}$ characterized by three cross-over compositions, $\left(\mathrm{Y}_{\mathrm{c}}\right)_{\gamma},\left(\mathrm{Y}_{\mathrm{c}}\right)_{\beta}$ and $\left(\mathrm{Y}_{\mathrm{c}}\right)_{\mathrm{I}}$.

Fig. 3. Concentration profiles for the $\mathrm{Fe}-\mathrm{Ni}-\mathrm{Al}$ couple $\gamma_{2} / \beta_{27}$ with concentrations expressed in (a) atom percent and (b) in relative concentrations $Y_{i}$; (c) the S-shaped path for the couple characterized by a virtual cross-over composition $\left(Y_{c}\right)_{1}$ at the interface.

Fig. 4. Concentration profiles for the Fe-Ni-Al couple $\gamma_{6} / \beta_{12}$ with concentrations in (a) atom percent and (b) relative concentrations; (c) the S-shaped diffusion path for the couple showing a cross-over composition $\left(\mathrm{Y}_{\mathrm{c}}\right)_{\beta}$ in the $\beta$ phase.

Fig. 5. (a) Concentration profiles and (b) S-shaped diffusion path with a virtual cross-over composition $\left(\mathrm{Y}_{\mathrm{c}}\right)_{1}$ for the $\mathrm{Cu}-\mathrm{Ag}-\mathrm{Au}$ couple $80 \mathrm{C} / 80 \mathrm{~S}$.

Fig. 6. (a) Concentration profiles and (b) S-shaped diffusion path with a virtual cross-over composition $\left(\mathrm{Y}_{\mathrm{c}}\right)_{\mathrm{I}}$ for the $\mathrm{Cu}-\mathrm{Ag}-\mathrm{Au}$ couple $60 \mathrm{C} / \mathrm{S}$. 


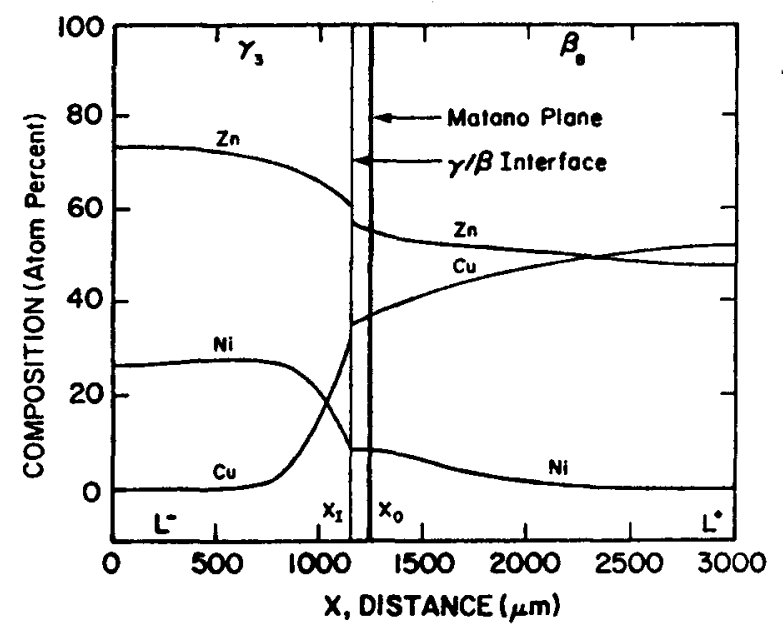

(a)

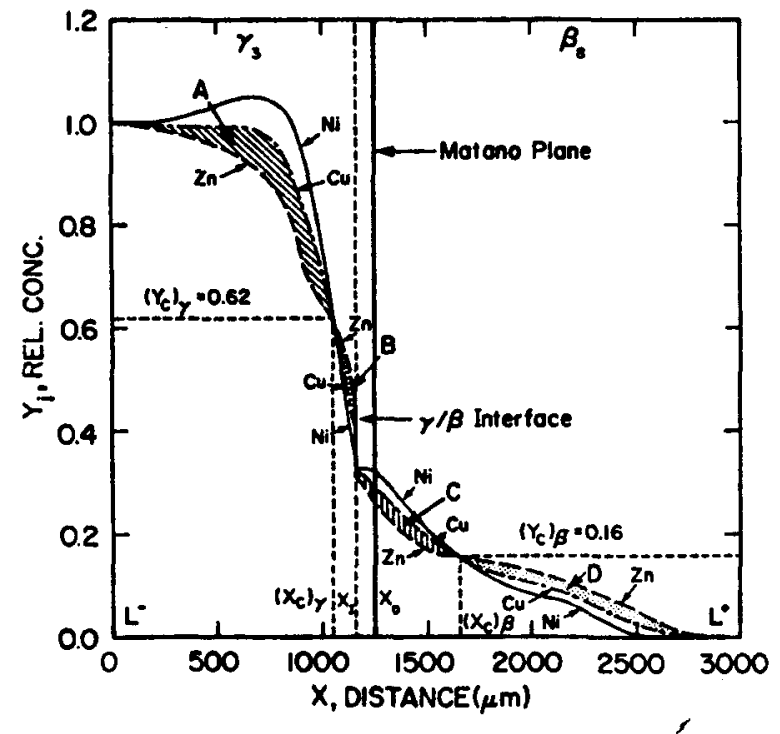

(b)

Fig. 1. Concentration profiles for the Cu-Ni-Zn couple $\gamma_{3} / B_{8}$ with conentrations expressed in (a) atom percent and (b) relative concentrations $Y_{i} ;(c)$ a.plot of $Y_{Z n}$ vs $Y_{C u}$ delineating a double S-shaped diffusion path with 3 cross-over compositions $\left(Y_{c}\right)_{Y},\left(Y_{C}\right)_{B}$ and $\left(Y_{c}\right)_{I}$. The experimental data points enclosed in circles correspond to compositions of the phases at the interface. The calculated path is shown by the dashed curve.

(c)

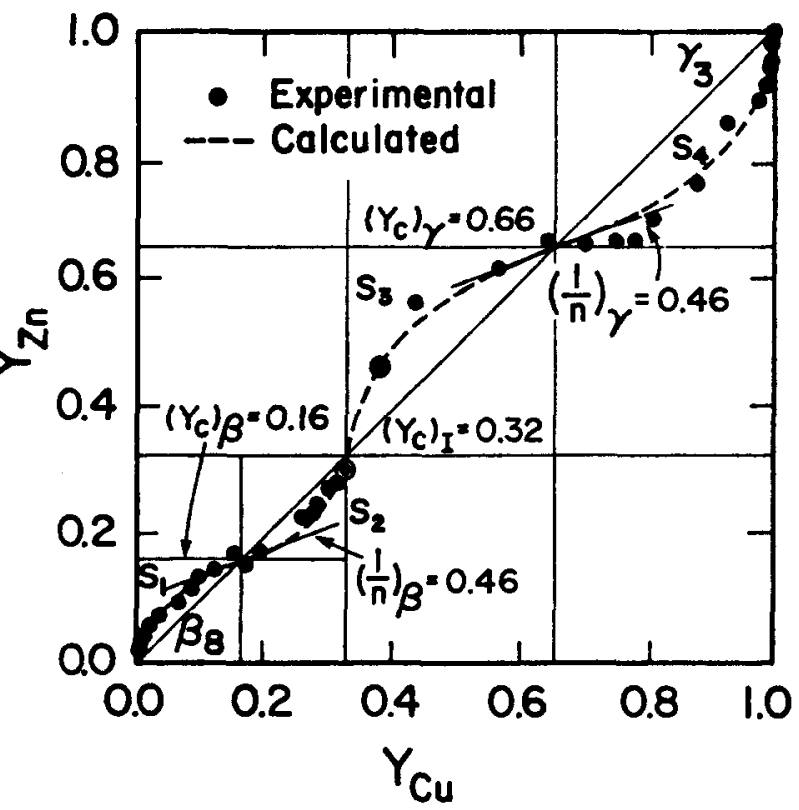




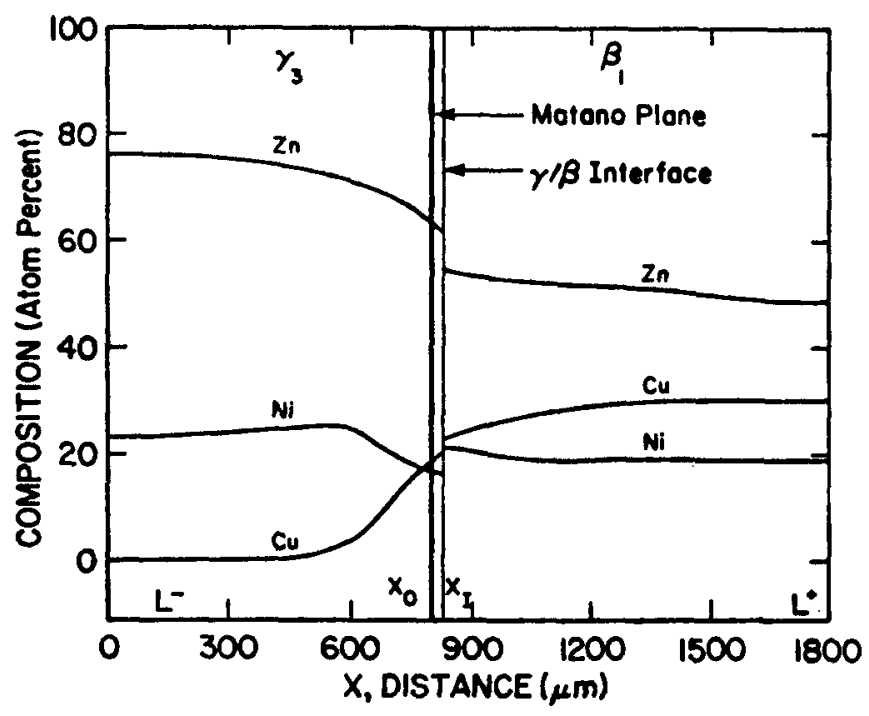

(a)

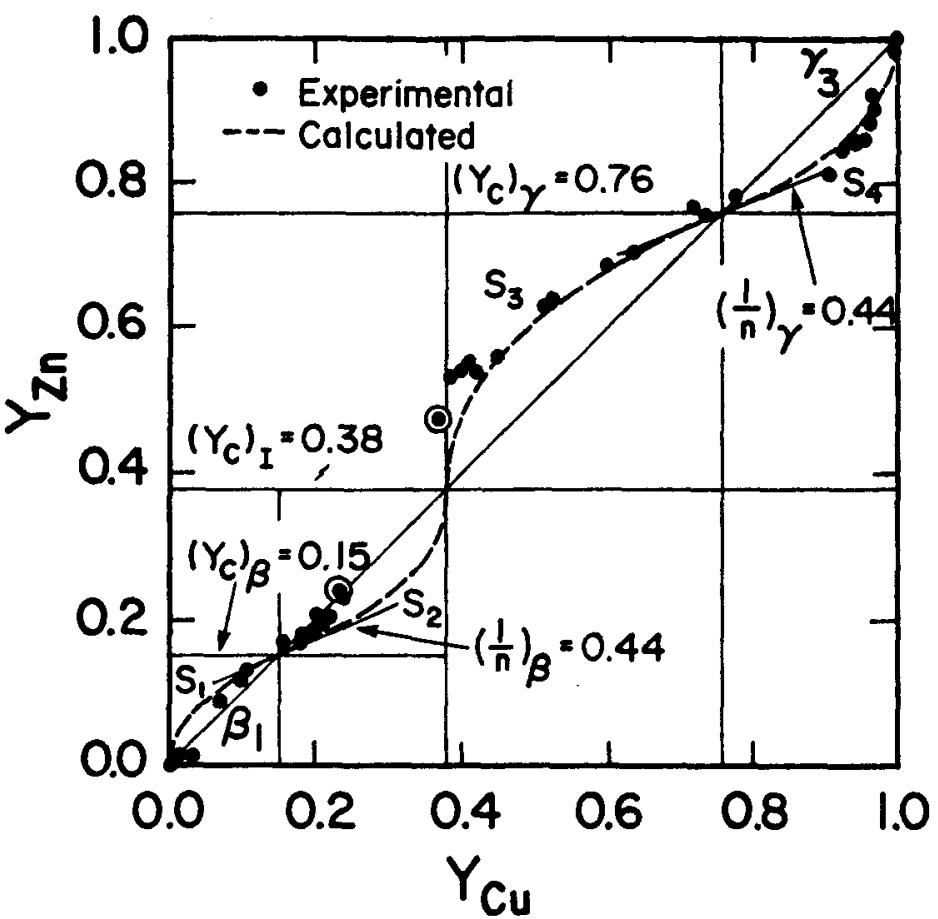

(b)

Fig. 2. (a) Concentration profiles and (b) double S-shaped diffusion path for the Cu-Ni-Zn couple $\gamma_{3} / B_{7}$ characterized by three crossover compositions, $\left(Y_{C}\right)_{\gamma},\left(Y_{C}\right)_{B}$ and $\left(Y_{C}\right)_{I}$. 

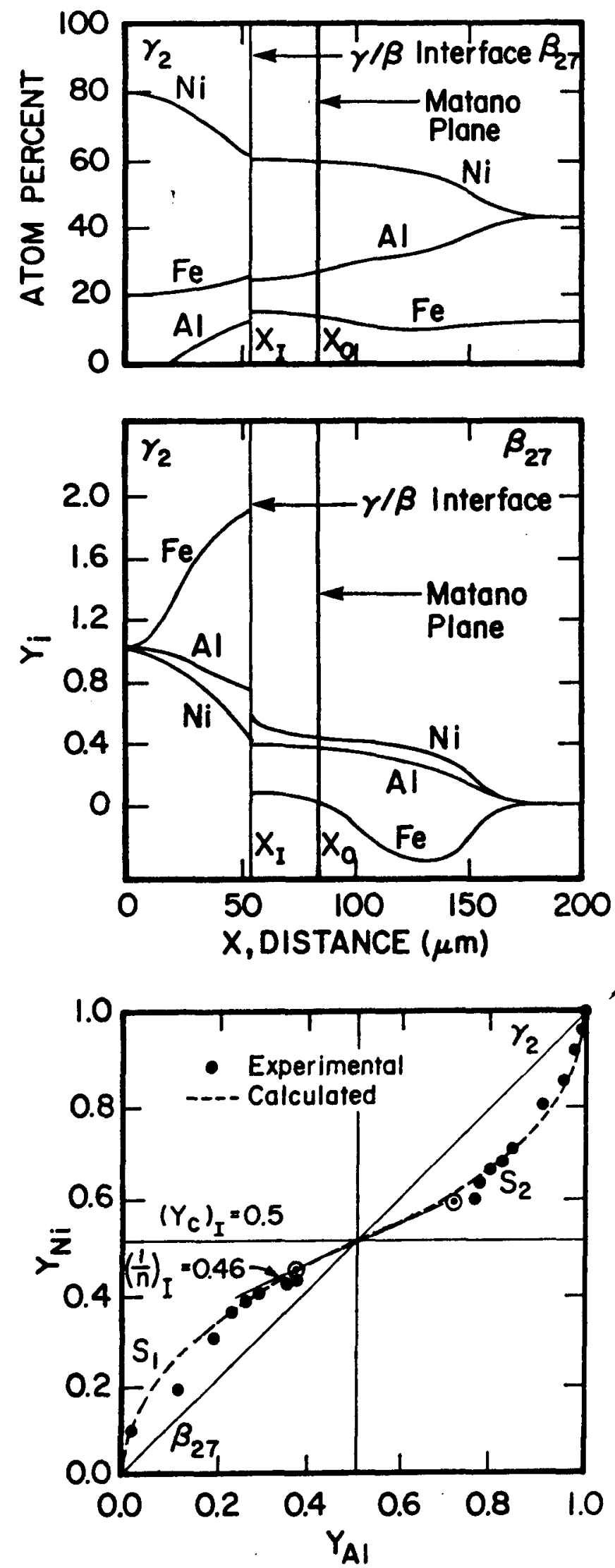

(a)

Fig. 3. Concentration profiles for the Fe-Ni-Al couple $\gamma_{2} / B_{27}$ with concentrations expressed in (a) atom percent and (b) in

(b) relative concentrations $Y_{i}$; (c) the S-shaped path for the couple characterized by a virtual cross-over composition $\left(\gamma_{c}\right)_{I}$ at the interface.

(c) 


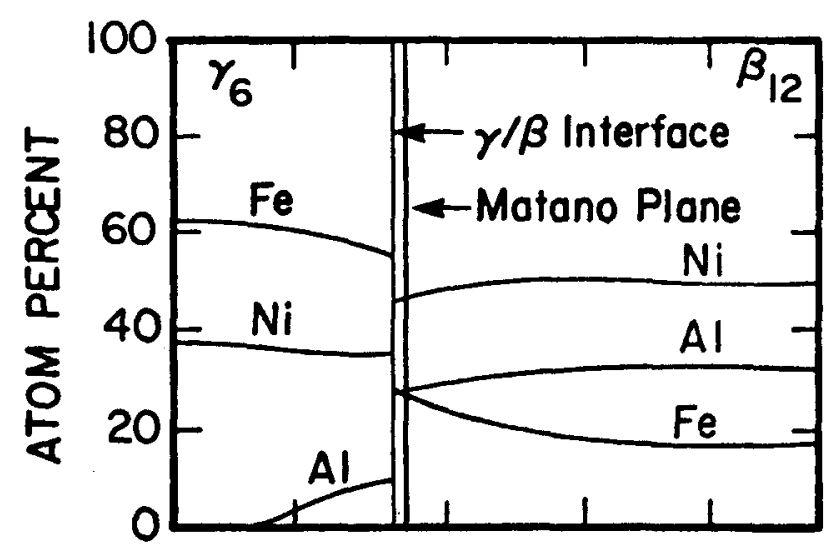

(a)

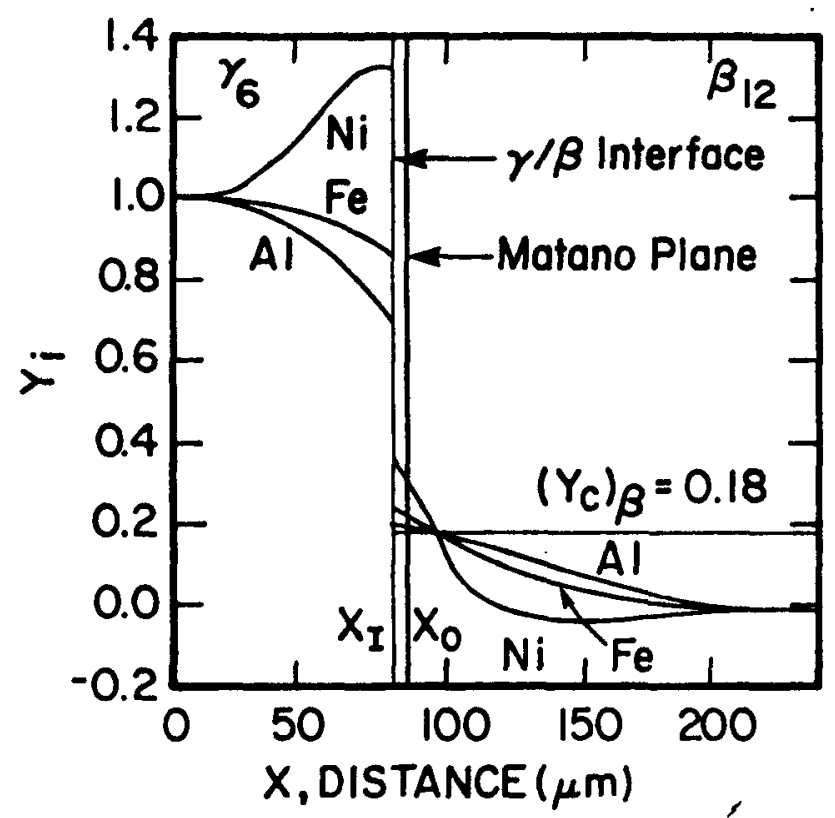

(b)

Fig. 4. Concentration profiles for the Fe-Ni-Al couple $\gamma_{6} / \beta_{12}$ with concentrations in (a) atom percent and (b) relative concentrations; (c) the S-shaped diffusion path for the couple showing a cross-over composition $\left(Y_{C}\right)_{B}$ in the $B$ phase.

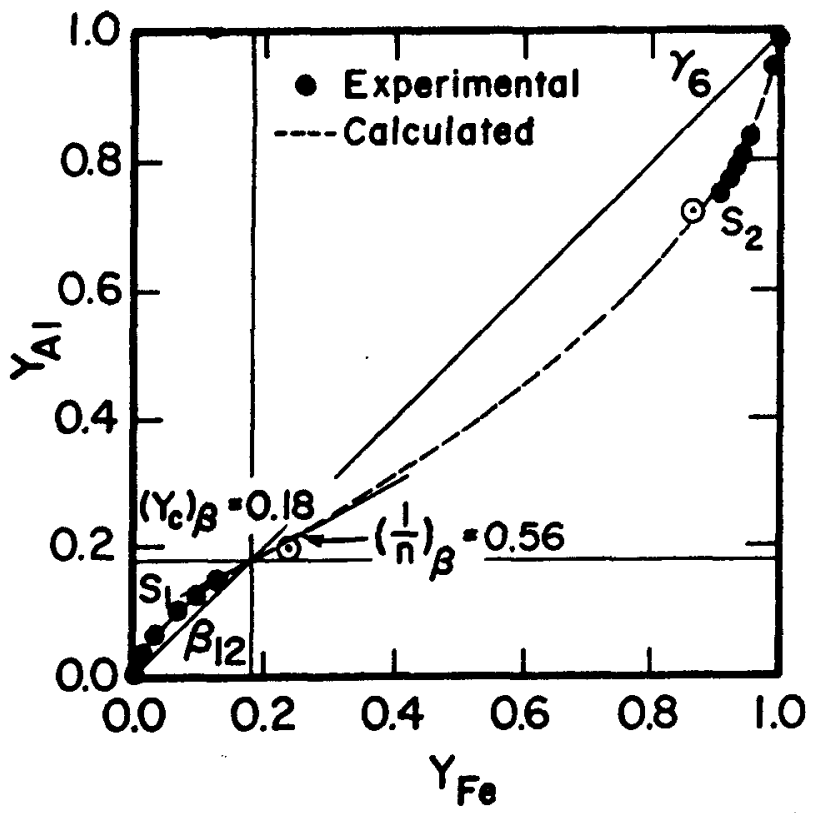

(c) 

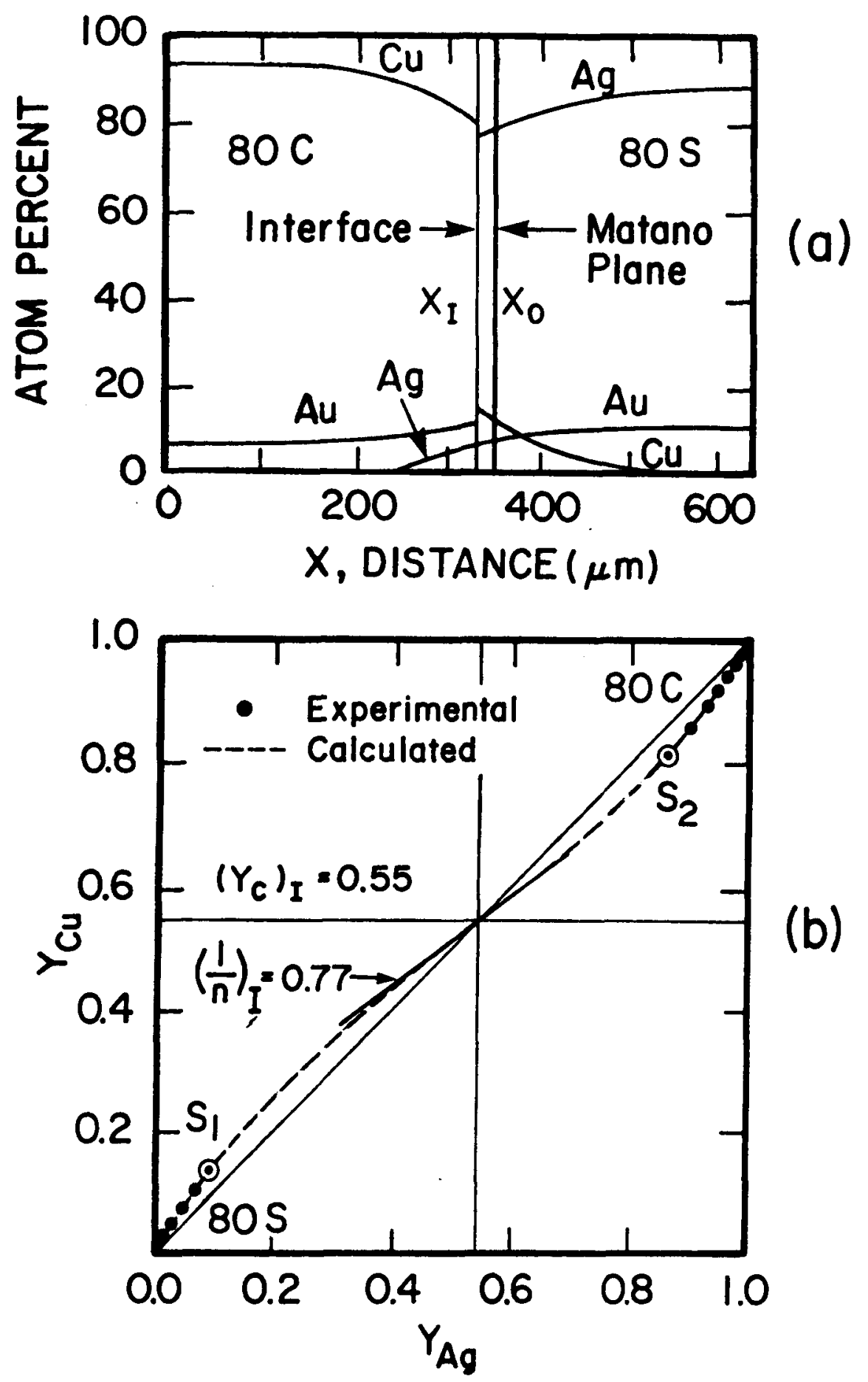

(b)

Fig. 5. (a) Concentration profiles and (b) S-shaped diffusion path with a virtual cross-over composition $\left(Y_{c}\right)_{I}$ for the $\mathrm{Cu}-\mathrm{Ag}-\mathrm{Au}$ couple $80 \mathrm{C} / 80 \mathrm{~S}$. 


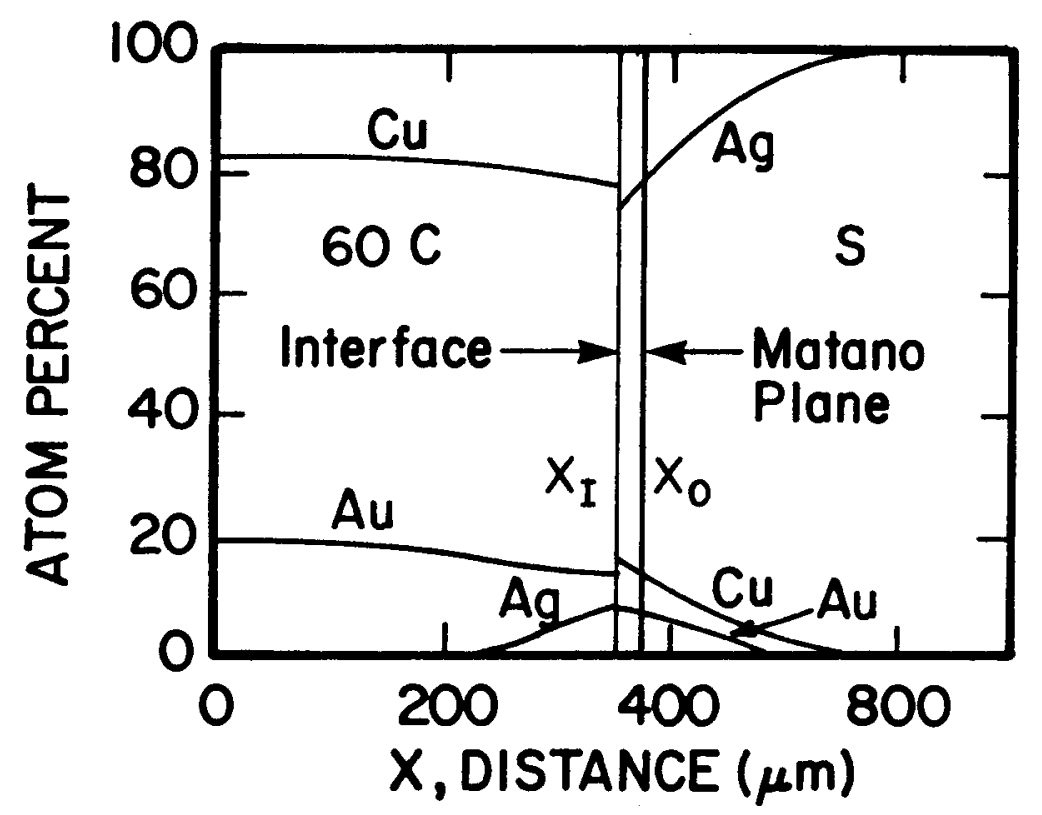

(a)

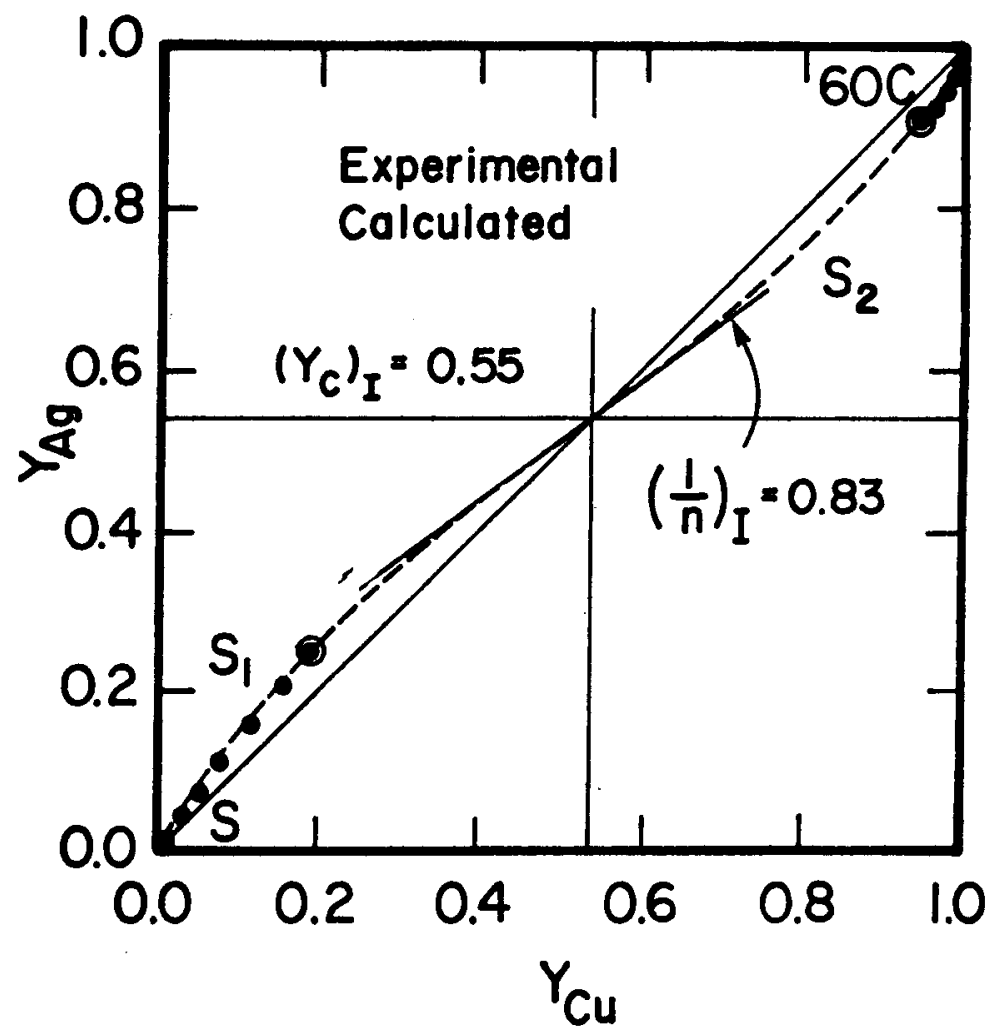

(b)

Fig. 6. (a) Concentration profiles and (b) S-shaped diffusion path with a virtual cross-over composition $\left(Y_{c}\right)_{I}$ for the $\mathrm{Cu}-\mathrm{Ag}-\mathrm{Au}$ couple $60 \mathrm{C} / \mathrm{S}$. 